\title{
Reduction in ST segment elevation after thrombolysis predicts either coronary reperfusion or preservation of left ventricular function
}

\author{
R K Saran, M Been, S S Furniss, T Hawkins, D S Reid
}

\begin{abstract}
The usefulness of a reduction in ST segment elevation to predict coronary reperfusion in myocardial infarction remains uncertain. ST segment changes and angiographic findings were compared in 45 patients soon after thrombolysis. The percentage ST segment change 3 hours after treatment (in the lead showing the greatest initial ST elevation) was compared with the TIMI perfusion grade (thrombolysis in myocardial infarction trial) obtained between 90 minutes and 3 hours after treatment. Global ejection fraction and regional wall motion were assessed by cineventriculography (11 (5) days (mean (SD))) and by gated blood pool imaging (44 (11) days). Prediction of coronary patency by a reduction of $>25 \%$ in ST segment elevation 3 hours after thrombolytic treatment had a sensitivity of $97 \%$ but a specificity of only $43 \%$. Where the ST segment elevation was reduced by $>25 \%$ the global ejection fraction was well maintained whether or not the infarct vessel was patent. In patients with a reduction of $<25 \%$ in ST elevation, the ejection fraction was significantly lower and regional wall motion abnormality more severe.
\end{abstract}

Reduction in ST elevation of $>25 \%$ within 3 hours of thrombolysis indicates either a patent infarct artery or preservation of left ventricular function. When the ST segment elevation does not fall by $>25 \%$ persistent coronary occlusion is likely (predictive accuracy $86 \%$ ) and is associated with a lower ejection fraction. These patients may benefit from further treatment or additional interventions.

Cardiothoracic Unit, Freeman Hospital, Newcastle upon Tyne R K Saran

$M$ Been

S S Furniss

T Hawkins

D S Reid

Correspondence to

Dr D S Reid, Cardiothoracic

Unit, Freeman Hospital,

Freeman Road, Newcastle

upon Tyne NE7 7DN.

Accepted for publication

27 February 1990 patients in whom thrombolysis does not lead to reperfusion ${ }^{34}$ and such patients may benefit from early additional interventions such as salvage angioplasty. A rapid reduction in ST
Treatment by intravenous thrombolysis in acute myocardial infarction reduces morand is preserves left ventricular funct detection of reperfusion may be a useful guide segment elevation, ${ }^{5}$ relief from chest pain, ${ }^{6}$ early peaking of serum concentrations of creatine kinase, ${ }^{7}$ and reperfusion arrhythmias ${ }^{8}$ are some of the markers used to predict reperfusion non-invasively. In a review of electrocardiographic studies after thrombolysis Bren et al concluded that when large groups are analysed, the magnitude of the reduction in ST elevation is greater in groups with reperfusion than in those without or in a control group. ${ }^{9}$ They suggested, however, that in individual patients reduction in ST segment elevation is of limited value in predicting reperfusion and left ventricular function. On the other hand, Hogg et al reported that the 12 lead electrocardiogram is a simple and useful method for determining reperfusion in individuals. ${ }^{10} \mathrm{We}$ therefore studied the usefulness of early changes in the ST segment in predicting vessel patency and preservation of left ventricular function after thrombolysis.

\section{Patients and methods}

This study was part of a randomised trial to investigate the effects of percutaneous transluminal coronary angioplasty immediately after thrombolytic treatment. Forty five consecutive patients with acute infarction who fulfilled the entry criteria for the above study were given intravenous anisoylated streptokinase plasminogen activator complex (anistreplase) between August 1987 and November 1988. The criteria for inclusion into the study were: (a) ischaemic chest pain lasting $>30$ minutes but < 4 hours; (b) ST segment elevation of at least $0.2 \mathrm{mV}$ in two or more precordial leads or $0.1 \mathrm{mV}$ in two or more standard limb leads; (c) aged $\leqslant 70$; $(d)$ gave consent to the study; (e) no contraindication to thrombolytic treatment or angiography.

A pretreatment 12 lead electrocardiogram was recorded and the sites of leads V1 to V6 were marked on the chest to ensure consistent electrode placement for subsequent electrocardiograms. All patients were given 30 units of anistreplase by intravenous injection over 5 minutes. Coronary angiography was performed at 60 minutes and at 90 minutes after treatment with anistreplase. Patients randomly allocated to percutaneous transluminal coronary angioplasty underwent balloon dilatation of the culprit lesion immediately after the 90 minute angiogram 
unless there was a left main stem lesion or the stenosis in the infarct artery was less than $50 \%$. Vessel patency was assessed 15 minutes after the last balloon inflation. The arterial sheath was left in position and heparin was infused at a rate of 1000 units per hour.

A repeat electrocardiogram was recorded at 3 hours after anistreplase treatment (mean (SD) 206 (35) minutes). Repeat coronary angiography was performed at 24 hours after which the sheath was removed.

\section{ELECTROCARDIOGRAPHIC ANALYSIS}

Electrocardiograms recorded before thrombolysis and 3 hours afterwards were analysed by an observer who was unaware of the angiographic findings or clinical details. The lead showing the greatest ST segment elevation at presentation was used for subsequen measurement of ST segments. We used callipers to measure ST elevation and we took the mean of three complexes. The isoelectric line was defined as the level of the preceding TP segment and ST segment elevation was measured at the $\mathrm{J}$ point. The mean change in ST segment elevation after thrombolytic treatment was expressed as a percentage reduction or increase from the initial value.

\section{CORONARY ANGIOGRAPHIC ANALYSIS}

The coronary angiograms were analysed by two observers who were unaware of the electrocardiographic results. Coronary perfusion was assessed by the TIMI (thrombolysis in myocardial infarction trial) criteria. ${ }^{11}$ TIMI grades 0 and 1 were classified as non-patent arteries and TIMI grades 2 and 3 as a patent artery. The collateral circulation was also evaluated on a scale of 0 to $3 .^{12}$ The collateral score was based on the injection that best opacified the occluded vessel. In grade 0 there was no filling, in grade 1 filling of side branches of the occluded vessel could be seen, while in grade 2 there was partial filling of the epicardial segment, and in grade 3 there was complete filling of the epicardial segment of the occluded vessel via collaterals.

\section{LEFT VENTRICULAR FUNCTION}

Left ventricular function was evaluated from biplane contrast cineventriculograms before hospital discharge at 11 (5) days and by gated blood pool imaging (technetium-99m labelled pyrophosphate) at 44 (14) days.

Contrast ventriculography was performed in 39 patients. It was not performed in patients who refused consent $(n=1)$, who had coronary bypass grafting $(n=1)$ or percutaneous transluminal angioplasty outside the protocol $(n=1)$, or who were considered too ill $(n=1)$ for the procedure. Practical reasons prevented two more patients from having contrast ventriculography. The ejection fraction was calculated from tracings taken by projecting the right anterior oblique view but four patients were excluded from analysis of global left ventricular function because of a previous myocardial infarction. We assessed regional wall motion by dividing the left anterior oblique projection into three segments (septal (1), inferoapical (2), posterolateral (3)) and the right anterior oblique into five segments (high anterior (4), low anterior (5), apical (6), inferior (7), and posterior (8)). Segments with normal motion were scored as zero whereas hypokinesia, akinesia, and dyskinesia were scored as 1,2 , or 3 respectively - so the lower the total score in the infarct territory the better the preservation of left ventricular function. To exclude the influence of prior myocardial infarction on the results we scored only those segments associated with the infarct related artery. The wall motion score was calculated from segments $1,4,5$, and 6 in anterior infarction and from segments $2,3,7$, and 8 in inferior infarction.

The gated blood pool study was performed in 44 patients (one patient refused and in one patient the image quality was too poor for analysis). The global left ventricular ejection fraction was calculated by a semi-automated double region method for the left anterior oblique view. The four patients with previous myocardial infarction were also excluded from this analysis.

The regional wall motion abnormality score was assessed by dividing the left anterior oblique projection into three segments and the left lateral projection into five segments and wall motion scores were graded as for the contrast ventriculograms.

\section{STATISTICAL ANALYSIS}

We calculated the sensitivity and specificity of a reduction in ST elevation of $>25 \%$ and $>50 \%$ for perfusion and for no reperfusion. Statistical significance was determined by a two-sample analysis of variance. A $p$ value of $<0.05$ was regarded as significant.

\section{Results}

The mean age of the patients was 55 years (range 30-69). Forty two were men. Twenty five had an anterior infarction and 20 an inferior infarction. The mean interval from onset of chest pain to anistreplase treatment was 153 minutes (range 50 to 240). Table 1 shows the age, culprit artery, time from onset of symptoms to anistreplase administration, previous myocardial infarction if any, percentage reduction in ST elevation at 3 hours, TIMI grading at 90 minutes and 24 hours, and global ejection fraction in each of the 45 patients.

In 31 of the 45 patients the culprit coronary artery was patent 90 minutes after anistreplase or after percutaneous transluminal coronary angioplasty. All but one of these 31 patients showed a reduction in $\mathrm{ST}$ segment elevation by $>25 \%$ at 3 hours (table 2). Thus our results show that reduction in ST segment elevation of $>25 \%$ had sensitivity of $97 \%$ in predicting coronary patency. This compares with a sensitivity of $68 \%$ when we used the criterion of a reduction of $>50 \%$. ST segment elevation was reduced by $>25 \%$ in eight of 14 patients with a persistently occluded infarct related artery, indicating a specificity of only $43 \%$ for determining patency by this criterion. 
Table 1 Individual patient details, reduction in ST elevation at 3 hours, TIMI perfusion grade, and global ejection fraction at 6 weeks

\begin{tabular}{|c|c|c|c|c|c|c|c|c|}
\hline $\begin{array}{l}\text { Patient } \\
\text { No }\end{array}$ & Age (yr) & Infarct vessel & Prior $M I$ & $\begin{array}{l}\text { Symptom } \\
\text { duration (min) }\end{array}$ & $\begin{array}{l}\text { ST } \\
\text { reduction (\%) }\end{array}$ & $\begin{array}{l}\text { TIMI grade at } \\
90 \text { min }\end{array}$ & $24 \mathrm{~h}$ & $\begin{array}{l}\text { Global } \\
\text { EF }(\%)\end{array}$ \\
\hline $\begin{array}{r}1 \\
2 \\
3 \\
4 \\
5 \\
6 \\
7 \\
8 \\
9 \\
10 \\
11 \\
12 \\
13 \\
14 \\
15 \\
16 \\
17 \\
18 \\
19 \\
20 \\
21 \\
22 \\
23 \\
24 \\
25 \\
26 \\
27 \\
28 \\
29 \\
30 \\
31 \\
32 \\
33 \\
34 \\
35 \\
36 \\
37 \\
38 \\
39 \\
40 \\
41 \\
42 \\
43 \\
44 \\
45\end{array}$ & $\begin{array}{l}46 \\
62 \\
51 \\
45 \\
42 \\
62 \\
63 \\
53 \\
47 \\
63 \\
47 \\
48 \\
66 \\
57 \\
57 \\
65 \\
65 \\
58 \\
56 \\
44 \\
47 \\
69 \\
45 \\
68 \\
53 \\
30 \\
48 \\
59 \\
61 \\
46 \\
62 \\
48 \\
58 \\
66 \\
55 \\
59 \\
63 \\
64 \\
55 \\
48 \\
59 \\
55 \\
49 \\
61 \\
65\end{array}$ & $\begin{array}{l}\text { LAD } \\
\text { RCA } \\
\text { LAD } \\
\text { RCA } \\
\text { RCA } \\
\text { RCA } \\
\text { LAD } \\
\text { LAD } \\
\text { LAD } \\
\text { Cx } \\
\text { Cx } \\
\text { LAD } \\
\text { LAD } \\
\text { RCA } \\
\text { LAD } \\
\text { LAD } \\
\text { RCA } \\
\text { RCA } \\
\text { LAD } \\
\text { RCA } \\
\text { Cx } \\
\text { LAD } \\
\text { LAD } \\
\text { LAD } \\
\text { LAD } \\
\text { LAD } \\
\text { RCA } \\
\text { LAD } \\
\text { LAD } \\
\text { LAD } \\
\text { LAD } \\
\text { RCA } \\
\text { LAD } \\
\text { Cx } \\
\text { LAD } \\
\text { RCA } \\
\text { RCA } \\
\text { LAD } \\
\text { LAD } \\
\text { RCA } \\
\text { LAD } \\
\text { Cx } \\
\text { RCA } \\
\text { RCA } \\
\text { LAD }\end{array}$ & 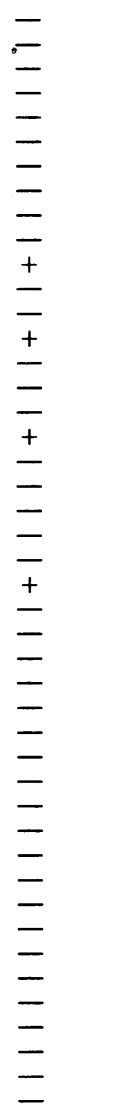 & $\begin{array}{r}200 \\
92 \\
64 \\
180 \\
130 \\
89 \\
118 \\
150 \\
149 \\
230 \\
85 \\
175 \\
155 \\
137 \\
95 \\
52 \\
150 \\
135 \\
192 \\
229 \\
240 \\
220 \\
110 \\
185 \\
210 \\
101 \\
150 \\
218 \\
240 \\
195 \\
195 \\
70 \\
225 \\
223 \\
115 \\
88 \\
110 \\
190 \\
140 \\
92 \\
175 \\
158 \\
193 \\
132 \\
50\end{array}$ & $\begin{array}{r}66 \\
66 \\
52 \\
80 \\
50 \\
66 \\
80 \\
33 \\
55 \\
100 \\
75 \\
75 \\
65 \\
68 \\
69 \\
50 \\
42 \\
100 \\
37 \\
38 \\
75 \\
-60 \\
80 \\
30 \\
73 \\
36 \\
7 \\
74 \\
-42 \\
52 \\
6 \\
-70 \\
66 \\
75 \\
75 \\
66 \\
66 \\
57 \\
87 \\
66 \\
-200 \\
33 \\
55 \\
66 \\
83 \\
30 \\
-300\end{array}$ & $\begin{array}{l}3 \\
3 \\
2 \\
2 \\
3 \\
3 \\
0 \\
3 \\
2 \\
3 \\
2 \\
2 \\
2 \\
0 \\
3 \\
2 \\
3 \\
0 \\
2 \\
0 \\
2 \\
0 \\
2 \\
3 \\
33 \\
3 \\
1 \\
1 \\
2 \\
0 \\
0 \\
3 \\
1 \\
3 \\
1 \\
3 \\
33 \\
3 \\
3 \\
3 \\
0 \\
3 \\
0 \\
2 \\
1\end{array}$ & $\begin{array}{l}3 \\
3 \\
0 \\
3 \\
1 \\
3 \\
0 \\
3 \\
3 \\
3 \\
3 \\
3 \\
3 \\
0 \\
3 \\
3 \\
0 \\
2 \\
2 \\
3 \\
0 \\
3 \\
2 \\
1 \\
3 \\
2 \\
2 \\
0 \\
0 \\
5 \\
3 \\
3 \\
3 \\
3 \\
3 \\
3 \\
3 \\
3 \\
3 \\
3 \\
3 \\
2 \\
0 \\
0\end{array}$ & $\begin{array}{l}54 \\
63 \\
40 \\
30 \\
48 \\
51 \\
62 \\
48 \\
58 \\
52 \\
26 \\
34 \\
29 \\
45 \\
27 \\
57 \\
54 \\
21 \\
28 \\
33 \\
6 \\
28 \\
39 \\
52 \\
52 \\
42 \\
33 \\
53 \\
45 \\
20 \\
61 \\
36 \\
\star \\
59 \\
60 \\
38 \\
57 \\
26 \\
50 \\
51 \\
68 \\
48 \\
45 \\
20\end{array}$ \\
\hline
\end{tabular}

${ }^{\star}$ Technically poor image; LAD, left anterior descending artery; RCA, right coronary artery; Cx, circumflex artery; MI, myocardial infarction; $\mathrm{EF}$, ejection fraction.

Table 2 Percentage reduction or increase in ST segment elevation at 3 hours in patients with and without coronary perfusion

\begin{tabular}{lcllll}
\hline & \multicolumn{4}{l}{$\begin{array}{l}\text { Percentage reduction in ST segment } \\
\text { elevation }\end{array}$} \\
\cline { 2 - 5 } $\begin{array}{l}\text { Coronary patency } \\
\text { (TIMI grade) }\end{array}$ & $>50 \%$ & $25-50 \%$ & $<25 \%$ & increase \\
\hline $0-1$ & 7 & 1 & 2 & 4 \\
$2-3$ & 21 & 9 & 0 & 1 \\
\hline
\end{tabular}

In five patients the ST segment elevation increased further and in two patients the reduction in ST segment elevation was $<25 \%$. In all but one of these patients the infarct related artery was occluded. The absence of a reduction of $>25 \%$ in ST segment elevation 3 hours after thrombolysis is highly specific $(97 \%)$ for coronary occlusion.

The perfusion and electrocardiographic data were used to divide the patients into four groups. Group $1(\mathbf{n}=30)$ comprised patients with a patent artery and a reduction of $>25 \%$ in ST elevation while group $2(n=1)$ was a patient with a patent artery and a reduction of $<25 \%$. Group $3(n=8)$ included those with a non-perfusing artery but a reduction of $>25 \%$ in ST elevation while group $4(n=6)$ comprised those with an occluded artery and a reduction of $<25 \%$ in ST segment elevation.
Group 2 was excluded from analysis because it contained only one patient. The figure shows a comparison of the global left ventricular ejection fraction measured by gated blood pool imaging in the remaining groups. The ejection fraction (mean (SD)) was highest in those with patent vessels (47 (13)\%) (group 1). This was

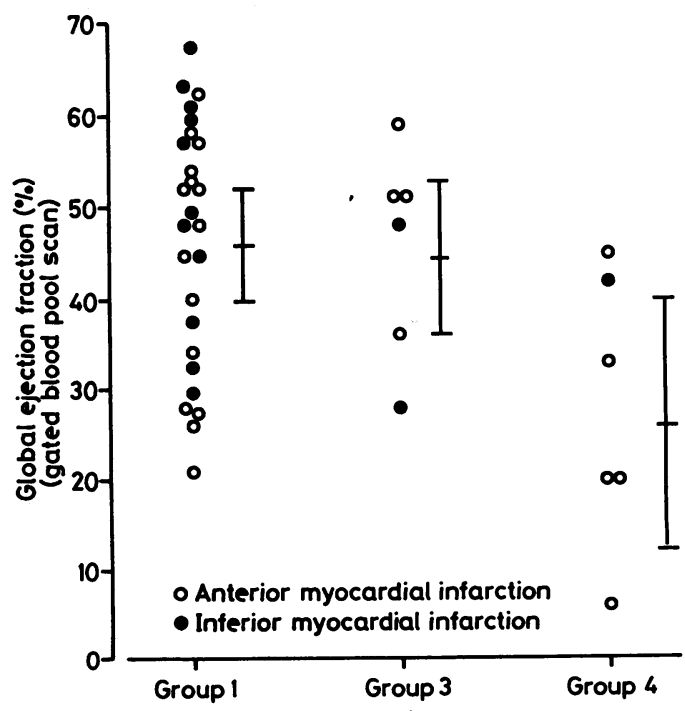

Left ventricular ejection fraction in patients with $\geqslant 25 \%$ reduction in ST elevation (group $1=$ patent, group $3=$ occluded) and in patients with $<25 \%$ reduction in ST segment elevation and occluded arteries (group 4). 
Table 3 Global ejection fraction and mean regional wall motion abnormality score in the different groups (mean (SD))

\begin{tabular}{|c|c|c|c|c|c|}
\hline \multirow[b]{2}{*}{ Group } & \multirow[b]{2}{*}{$\begin{array}{l}\text { Symptom } \\
\text { duration (min) }\end{array}$} & \multicolumn{2}{|c|}{ Ventriculogram $(n=39)$} & \multicolumn{2}{|c|}{ Gated blood pool scan ( $n=43)$} \\
\hline & & $\begin{array}{l}\text { Ejection } \\
\text { fraction }\end{array}$ & $\begin{array}{l}\text { Wall motion } \\
\text { score }\end{array}$ & $\begin{array}{l}\text { Ejection } \\
\text { fraction }\end{array}$ & $\begin{array}{l}\text { Wall motion } \\
\text { score }^{\star}\end{array}$ \\
\hline $\begin{array}{l}1 \\
3 \\
4\end{array}$ & $\begin{array}{l}145(56) \\
166(46) \\
171(65)\end{array}$ & $\begin{array}{l}55(14) \\
57(25) \\
40(9)\end{array}$ & $\begin{array}{l}2 \cdot 7(2) \\
3 \cdot 0(2) \\
4 \cdot 8(1)\end{array}$ & $\begin{array}{l}47(13) \\
46(11) \\
28(15)\end{array}$ & $\begin{array}{l}2 \cdot 5(2) \\
2 \cdot 4(3 \cdot 1) \\
4 \cdot 7(3 \cdot 2)\end{array}$ \\
\hline
\end{tabular}

* Mean regional wall motion score of infarct related segments.

Group 1-patent artery and $\geqslant 25 \%$ reduction in ST elevation.

Group 3 -non-perfusing artery but 2 - occluded artery and $<25 \%$ reduction in ST segment elevation.
Group

similar to group 3 where the ejection fraction was $46(11) \%$. Group 4 had a significantly lower $(p<0.05)$ ejection fraction $(28(15) \%)$. A similar trend was seen with the ejection fraction measured by cineventriculography (table 3). The duration of symptoms before thrombolysis was not significantly different in the three groups.

The mean regional wall motion abnormality score measured on the contrast left ventricular angiogram was 2.7 in group 1, 3.0 in group 3, and 4.8 in group 4 (not statistically significant). A similar trend was seen with mean regional wall motion score obtained by gated blood pool imaging.

Three of the eight patients in group 3 (occluded vessels and reduction in ST elevation $(>25 \%)$ ) had well developed collateral flow to the infarct related artery (collateral grade 2 and 3). These three patients had inferior wall infarction and there was complete filling of the posterior descending artery via collaterals. In four of the remaining five patients in group 3 there was reperfusion between 90 minutes and 24 hours after thrombolysis.

Two of the six patients in group 4 had poorly developed collaterals (grade 1) and no collateral flow was seen in the remaining four patients. In two of the patients in group 4 there was reperfusion between 90 minutes and 24 hours.

\section{Discussion}

Simple and rapid methods for determining perfusion state are required if decisions about additional treatment or procedures need to be made early after thrombolysis. Prediction from creatine kinase curves and from most Holter monitoring systems will only allow a retrospective diagnosis of reperfusion. It has been suggested that analysis of the ST segment by single or multiple electrocardiographic leads is useful but there is no consensus about the degree of reduction in ST segment elevation needed to predict reperfusion because different techniques and criteria have been used. The lead showing the greatest ST segment elevation was selected in this study primarily for simplicity so that a useful clinical tool might be defined, but also to allow comparison with many other studies. In addition it is highly likely that this lead would follow the same course both in time and magnitude as the sum of ST changes in all leads.

We found that an early reduction of ST segment elevation by $>25 \%$ after thrombolytic treatment for acute myocardial infarction is highly sensitive for coronary perfusion $(97 \%)$ but has poor specificity (43\%). Hogg et al reported a high sensitivity $(93 \%)$ for a fall of $>50 \%$ in the lead showing maximum ST elevation, with a specificity of $67 \% .^{10}$ There was, however, a wide variation in the mean (SD) time of the post-thrombolytic electrocardiogram (302 (141) minutes) in their study and perfusion criteria were not given. When we used a $50 \%$ reduction in ST elevation there was a fall in sensitivity to $68 \%$ and a slight improvement in specificity $(50 \%)$. Richardson et al reported a specificity of $67 \%$ but with a poor sensitivity $(26 \%)$ when a single lead showing the maximal ST segment elevation was used to predict coronary artery patency. ${ }^{13}$ They used a reduction of $2 \mathrm{~mm}$ in ST segment elevation or normalisation of the ST segment as the criteria for patency, and confirmation of angiographic patency was only performed at a mean of 6 days after thrombolytic treatment. The likelihood of spontaneous or late reperfusion in many of these patients seriously hampers the usefulness of Richardson et al's study in determining the accuracy of an early reduction in ST segment elevation in predicting early coronary perfusion.

Our study suggests that an early reduction in ST segment elevation is of limited value in predicting the patency of the coronary artery in an individual patient (low specificity). Perhaps more importantly the study shows that failure of ST segment elevation to be reduced by $>25 \%$ indicates persisting coronary occlusion. Von Essen et al also reported a persistence of or an increase in ST segment elevation in leads $I$, II, and III in nine out of 10 patients with unsuccessful thrombolysis. ${ }^{14}$ There remains, however, a separate group (group 3) with persistent occlusion in whom the ST segment falls to the same extent as in reperfusion. The ejection fraction and regional wall motion score in this group resembled values in the group with coronary perfusion. The TIMI group also reported a significant correlation $(p<0.01$; $r=0.43$ ) between the decline in ST elevation two hours after thrombolytic treatment and the residual left ventricular ejection fraction at discharge. ${ }^{15}$ The reason for the fall in the ST segment in the absence of reperfusion is unclear in these patients. It is unlikely that the ST segment fell in these patients because of more rapid death of myocardial cells because this would have resulted in a lower ejection 
fraction and higher score for regional wall motion abnormality.

In three (of eight patients in our study) the reduction in ST elevation was probably due to the presence of collaterals and in four (of the remaining five) it is possible that reperfusion occurred between 90 minutes and three hours because the infarct vessel was patent at 24 hours. This still leaves one patient in whom there were no collaterals and the infarct artery was still occluded at 24 hours.

We chose to assess the 12 lead electrocardiogram three hours after thrombolytic treatment but it may be that even earlier assessment would be of value. Von Essen et al showed that where there is a reduction in ST elevation much of this occurs within one hour of reperfusion. ${ }^{14}$

Whatever the explanation for the reduction in ST elevation our results suggest that a fall of $>25 \%$ in the lead showing maximal initial ST elevation within three hours of thrombolysis is indicative of either a patent infarct related coronary artery or preservation of left ventricular function despite coronary occlusion.

Thus reduction in ST elevation seems to select out a group of patients likely to have a good outcome. The remaining patients who do not show a fall in ST elevation of $>25 \%$ have both persistent coronary occlusion (specificity $97 \%$ ) and a lower ejection fraction and so may benefit from further treatment or acute interventions.

SSF was supported by the British Heart Foundation and RKS was a Commonwealth Fellow in Cardiology.

1 ISIS-2 (Second international study of infarct survival) Collaborative oroup. Randomised trial of intravenous streptokinase, oral aspirin, both, or neither among 17187 cases of suspected acute myocardial infarction: ISIS-2. Lancet 1988;ii:349-60.

2 White HD, Norris RM, Brown MA, et al. Effect of intravenous streptokinase on left ventricular function and early survival after acute myocardial infarction. $N$ Engl $J$ Med 1987;317:850-5.

3 Been M, Muir AL, de Bono DP. Left ventricular function after anisoylated plasminogen streptokinase activator complex. Drugs 1987;33(suppl 3):191-7.

4 Kennedy JW, Martin GV, Davis KB, et al. The Western Washington intravenous streptokinase in acute myocardial infarction randomized trial. Circulation 1988; 77:345-52.

5 Krucoff MW, Green CE, Satler LF, et al. Noninvasive detection of coronary artery patency using continuous ST-segment monitoring. Am J Cardiol 1986;57:916-22.

6 Lee G, Amsterdam EA, Low R, et al. Efficacy of percutaneous transluminal coronary recanalization utilizing streptokinase thrombolysis in patients with acute utilizing streptokinase thrombolysis in patients with acure

7 Been M, de Bono DP, Muir AL, Boulton FE, Hillis WS, Hornung R. Coronary thrombolysis with intravenous Hornung $\mathbf{R}$. Coronary thrombolysis with intravenous 26921. Br Heart J 1985;53:253-9.

8 Rutsch W, Schartl M, Mathey D, et al. Percutaneous transluminal coronary recanalisation: procedure, results, and acute complications. Am Heart $J$ 1981;102:1178-81.

9 Bren GB, Wasserman AG, Ross AM. The electrocardiogram in patients undergoing thrombolysis for myocardial infarction. Circulation 1987;76(suppl II): 18-24.

10 Hogg KJ, Hornung RS, Howie CA, Hockings N, Dunn FG, Hillis WS. Electrocardiographic prediction of coronary artery patency after thrombolytic treatment in acute myocardial infarction: use of the ST segment as a noninvasive marker. Br Heart $J$ 1988;60:275-80.

11 Chesebro JH, Knatterud G, Roberts R, et al. Thrombolysis in myocardial infarction (TIMI) trial, phase 1: a comparison between intravenous tissue plasminogen activator and intravenous streptokinase. Circulation 1987; 76:142-54.

12 Hirai T, Fujita $M$, Nakajima $H$, et al. Importance of collateral circulation for prevention of left ventricular aneurysm formation in acute myocardial infarction. Circulation 1989;79:791-6.

13 Richardson SJ, Morton P, Murtagh JG, et al. Relation of coronary arterial patency and left ventricular function to electrocardiographic changes after streptokinase treatment during acute myocardial infarction. Am J Cardio 1988;61:961-5.

14 Von Essen R, Schmidt W, Uebis R, et al. Myocardial infarction and thrombolysis: electrocardiographic short term and long term results using precordial mapping. $B_{r}$ Heart J 1985;54:6-10.

15 Bren GB, Wasserman AG, Sheehan FH, Forman S, Dodge HT, Ross AM, for the TIMI investigators. Electrocardiographic evolution during acute myocardial infarction as a correlate of left ventricular functional outcome [Abstract]. Circulation 1985;72 (suppl III):149. 